\title{
entre a performance e a escrita: \\ UM OLHAR SOBRE A LITERATURA EXPANDIDA CONTEMPORÂNEA NA POESIA MARGINAL-PERIFÉRICA DE NÍVEA SABINO
}

Between performance and writing: a look at contemporary expanded literature in marginal-peripheral poetry by Nívea Sabino

\section{Luiz Eduardo Rodrigues de Almeida Souza ${ }^{1}$ Rogério Meira Coelho²}

Resumo: Pretende-se neste artigo construir uma leitura analítica sobre as vozes, corpos e espaços entre a performance e a escrita da poeta Nívea Sabino, que participa da cena/ movimento/circuito dos saraus e slams marginais-periféricos de Belo Horizonte (MG). Para isso, apresentamos uma breve incursão pelas estéticas do marginal e do periférico em contraponto ao espaço/lugar da literatura contemporânea contestada, relacionando o contexto sociocultural dessa produção literária à margem com as vozes, escritas e performances do movimento e circuito de saraus e slams. Da produção escrita de Nívea, teremos como base alguns trechos dos poemas do livro Interiorana, como suporte, para entendermos uma literatura que nasce e é criada no "entre" a performance e a escrita.

Palavras-chave: Voz; Escrita; Performance; Espaço; Literatura Marginal-Periférica; Literatura Contemporânea.

Abstract: The aim of this article is to build an analytical reading about the voices, bodies and spaces between the performance and the writing of the poet Nivea Sabino who participates in the scene / movement / circuit of the marginal-peripheral recitals and slams of Belo HorizonteMG. For this, we present a brief incursion into the aesthetics of the marginal and the peripheral as opposed to the space / place of the contested contemporary literature, relating the socio-cultural context of this literary production on the margin with the voices, writings and performances of the movement and circuit of recitals and slams. From Nívea's written production we will have as a base one of the poems from the book Interiorana, as a support, to understand a literature that is born and created in the "between" of performance to writing.

Keywords: Voice; Writing; Performance; Space; Peripheral Marginal Literature; Contemporary Literature.

1 Doutorando em Estudos de Linguagens/CEFET-MG. E-mail: luizeduardordealmeidasouza@gmail.com

2 Doutorando em Estudos Literários/UFMG. E-mail: rogeryocoelho@gmail.com. 
A poesia falada não vive presa na livraria (SABINO, Nívea, 2016, p. 7)

Nesse verso da epígrafe que está na abertura do livro Interiona, da poeta Nívea Sabino, publicado pela Padê Editorial em 2016, encontramos uma implicação notável de híbrido; de dialética imagem e de justaposição entre "fala" e "escrita". A autora, reconhecidamente, é participante do advento da poesia e literatura marginal-periférica, um movimento amplo que abrange saraus e slams ${ }^{3}$ espalhados pelo Brasil e outros lugares do mundo. Pretendemos olhar para esta autora e este movimento/cena literário como um índice de contraponto ao sistema/campo literário da literatura brasileira contemporânea.

Este artigo celebra o encontro entre dois pesquisadores (também fruidores e poetas dos saraus e slams) que unem elementos das respectivas áreas do conhecimento, linguística e literatura, no intuito de transitar mais amplamente nesses universos. Inúmeras possibilidades se apresentam no diálogo entre as áreas afins, no que toca tanto a experiência da análise discursiva, quanto os estudos literários. A poesia falada, apresentada como literatura expandida e performance poética na profusão de signos e semioses, corrobora para uma pesquisa ampla que excede os campos da língua e da literatura. Nesse nomadismo investigativo, a história, a antropologia, a geografia, a ciência da voz, a sociologia, entre outros campos científicos, poderiam ser trazidos à luz do movimento de saraus e slams marginais contemporâneos.

3 O slam é uma competição de poesia falada criada na década de 1980 por Marc K. Smith em Chicago, nos Estados Unidos. Diversas pesquisas apontam seu surgimento, bem como as especificidades do movimento que está presente em diversos países, como relata a atriz-mc Roberta Estrela D'Alva: "Poderíamos definir o poetry slam, ou simplesmente slam, de diversas maneiras: uma competição de poesia falada, um espaço para livre expressão poética, uma ágora onde questões da atualidade são debatidas, ou até mesmo mais uma forma de entretenimento. De fato, é difícil defini-lo de maneira tão simplificada, pois, em seus 25 anos de existência, o poetry slam se tornou, além de um acontecimento poético, um movimento social, cultural, artístico que se expande progressivamente e é celebrado em comunidades em todo o mundo." (D'ALVA, 2011, p. 120). A competição ganhou vários formatos no mundo inteiro, porém o princípio de serem apresentados textos autorais vigora em sua totalidade, variando apenas no tempo de apresentação, número de jurados e formatos individuais ou de duplas, entre outros. 
Trazemos aqui um fator do contemporâneo da literatura marginal e/ou periférica 4 criada e cultivada nos espaços da rua, ou espaços convencionados, agregados a ela, que, por meio do corpo, revela a força expressiva da voz poética. Essa mesma voz em performance está colocada anteriormente à publicação impressa gráfica no suporte livro de uma editora, promovendo a circulação da obra por livrarias do mercado/sistema cultural e literário. A poesia falada ganha, como declara Nívea Sabino, amplitude na voz, na performance, no corpo, nos encontros que ela promove, muito antes do objeto livro.

Com essa reflexão inicial sobre as aproximações e distanciamentos entre a performance da poesia falada e a escrita, a saber de um movimento contemporâneo de saraus periféricos e slams, iremos discorrer sobre alguns elementos imprescindíveis neste contexto. A dinamização da "voz", na contemporaneidade, como um aspecto de resistência é tratado pelo estudioso das poéticas da oralidade Paul Zumthor (2014) a partir da seguinte ponderação analítica:

A civilização dita tecnológica ou pós-industrial está em vias [...] de sufocar em todo o mundo o que subsiste das outras culturas e de nos impor o modelo de uma brutal sociedade do consumo. Mas na própria medida dessa expansão e diante da ameaça que ela traz, o que cada vez mais resiste no mundo de hoje? Resistem, sem intenção necessariamente de contestação ou de recusa, nos media, nas artes, na poesia, nas próprias formas da vida social (a publicidade, a política...), as formas de expressão corporal dinamizadas pela voz. (ZUMTHOR, 2014, p. 62).

As vozes marginais da literatura periférica dos saraus e slams estariam nesse processo de resistência ao campo literário institucionalizado e à sociedade da informação tecnológica, indaga-se. Desse modo, sobre a ressignificação

4 A partir daqui iremos tratar do termo "literatura marginal-periférica", valendo-se da poesia marginal contemporânea, produzida por artistas oriundos das periferias urbanas, que difere daquele movimento produzido na década de 1970. O termo "periférico" aparece na publicação de "O Ser Periférico" (2013), na tese de doutoramento de Tiarajú Pablo D'Andrea. Pesquisador em sociologia, periférico, da Universidade de São Paulo, ele experimenta o que chama de "pistas" sobre a diferenciação entre suburbano e periférico. Assim, autoriza-se o termo periferia, tomando em consideração alguns textos, surgidos de autores autodenominados "marginais" ou "periféricos" desde a década de 1990. Podemos perceber suas defesas e autoafirmações por meio de um nome que os representa, em que se alternam essas nominações criadas, geradas, por esses(as) escritores(as). 
internacional dessas performances e vozes poéticas da rua transmitidas pelo Slam - campeonato de poesia falada - Roberta Estrela D'Alva, precursora e fundadora dessa modalidade literária no Brasil em 2008, traz a seguinte reflexão sobre o uso dessa voz poética às vésperas da etapa nacional, em São Paulo, dessa competição em um evento do Slam Resistência5, em 2016:

[...] é só uma desculpa a competição para que aconteça isso, para que as pessoas prestem atenção de novo não é apenas na poesia só, mas que a gente fique quieto pra ouvir o outro falar né [...] porque num mundo onde a gente não consegue mais se escutar, você parar e prestar atenção numa pessoa que está se expressando ali durante 3 minutos que seja [...] porque em meia hora se cada um falar 3 minutos dá pra falar 10 pessoas, então é democrático também (SLAM RESISTÊNCIA, 2016).

Escutar esta fala da atriz-mc e slamer Roberta Estrela D'Alva (ativista do Slam Zona da Palavra Autônoma - ZAP, de São Paulo) nos remete àquela ponderação analítica do PaulZumthor de que a expressão vocal vem resistindo em espaços democráticos de inclusão de vozes e corpos políticos como é o espaço do slam. Dessa maneira, incluímos a voz poética da performer e escritora Nívea Sabino nesse contexto sociocultural da produção literária à margem do sistema literário brasileiro contemporâneo. Centenas de comunidades de saraus e slams, espalhados pelo Brasil, colocam-se como movimentos, ou espaços alternativos de criação/produção de literatura.

A trajetória de Nívea Sabino, por sua vez, tem um vínculo com o Sarau dos Vagal, realizado na cidade de Nova Lima (MG), que surge em 2012, e com o Coletivoz, Sarau de Periferia de Belo Horizonte (MG), desde 2008, precursor dessa cena literária marginal. Esses espaços de saraus periféricos foram primordiais tanto para o desenvolvimento das performances, quanto para a difusão de seus textos, posteriormente publicados. Porém, foi no Slam Clube da Luta $-1^{\circ}$ slam de Belo Horizonte, iniciado em 2014 -, que

5 "Através da participação e competição de spoken world, campeonato de poesias faladas, no Slam da Guilhermina, o segundo slam do país, Del Chaves (idealizador [do Slam Resistência]), junto aos protestos que tomaram as ruas em 2013/2014, sentiu o chamado pra começar esta nova modalidade de intervenções poéticas num local de reuniões de mov. sociais com intuito de potencializar tanto os protestos quanto os poetas/poetisas desta cena emergente!". Este slam acontece "Toda primeira segunda do mês na Praça Roosevelt.

No escadão da Roosevelt com a Rua Augusta." Disponível em: https://www.facebook.com/slamresistencia. Acesso em: 29 nov. 2017. 
seus poemas ganhariam, na forma falada-vocalizada, espaço e visibilidade para além dos circuitos de sua cidade. Soma-se a esse percurso literário de Sabino, o ativismo no movimento de saraus e slams periféricos associado ao movimento de arte negra, ao feminismo e ao Fórum de Juventudes da região metropolitana de $\mathrm{BH}$.

Dessas primeiras inflexões em torno da criação literária da novalimense Nívea Sabino e de sua relação com a literatura marginal-periférica dos saraus/ slams, buscaremos neste artigo um olhar sobre uma leitura das vozes, corpos e espaços em sua performance poética que traga alguns traços constituintes desses conceitos no campo da literatura expandida contemporânea. Da produção escrita de Nívea, teremos como base alguns trechos dos poemas de Interiorana (2016), como suporte, para entendermos uma literatura que nasce no "entrelugar", da performance à escrita. Com isso, inicialmente, será apresentada uma breve incursão pelo marginal-periférico e a literatura contemporânea, e a relação dessa produção literária à margem com o movimento e o circuito de saraus e slams.

\section{a literatura marơinal-periférica dos saraus e "slams" O movimento em São Paulo}

A partir de uma breve contextualização histórica e literária, identificam-se algumas características sociais, econômicas e culturais que trazem distinções entre a poesia marginal/geração mimeógrafo (1970-1980) e a literatura marginal-periférica da nova geração de escritores de rua, que surge no período de 1990 e 2000, nas metrópoles urbanas do Brasil. Enquanto que no período de 1970-1980 os poetas marginais eram da classe média, estudantes universitários do centro-sul do Rio de Janeiro, os escritores periféricos se originam das classes populares, moradores de favelas, detentos em presídios, "minorias" sócio-étnico-raciais etc.

Grifamos a palavra "minorias" aqui, entendendo que essas parcelas da sociedade - a população negra, a pobre e a marginalizada, caracterizadas assim, representam, na verdade, "milhares de minorias silenciadas", como bem nos diz um poema escolhido para nossa análise "Seguimos na trilogia do não faz mal: - mulher, negra e pobre!" (SABINO, 2018, p. 112). Portanto, representam a maioria das brasileiras, "minorizadas" pelo poder hegemônico 
de uma elite branca, rica e heteronormativa quanto às tomadas de decisões de políticas estruturais.

Essa perspectiva é entendida assim na obra da autora indiana Gayatri Spivak (1942), Pode o subalterno falar? (1985), como uma condição de "não voz" das mulheres e grupos subalternos, colonizados, marginalizados ou excluídos. Tal condição reafirma a impossibilidade de terem voz, de serem ouvidos, pois a exclusão social, o confinamento pós-colonialista, escravista, deixa-os à mercê da representação por meio dos discursos hegemônicos, e não de sua própria voz. Nívea Sabino, nesse contexto, afronta a subalternidade imposta pelo campo hegemônico, uma vez que está "envolvida" de todas as maneiras, como diz Spivak: "A questão da mulher parece ser a mais problemática nesse contexto. Evidentemente, se você é pobre, negra e mulher, está envolvida de três maneiras" (SPIVAK, 2010, p. 85).

Tomando como um exemplo dessa origem sociocultural, em que ressurge o termo "literatura marginal", concentramos na favela do Capão Redondo, na zona sul de São Paulo, cuja realidade foi retratada na obra Capão Pecado, do escritor e rapper Ferréz, e publicada no ano de 2000 (NASCIMENTO, 2006). Este morador dessa favela no distrito de Capão Redondo na capital paulista, com a publicação independente de sua "ficção da realidade" (palavras do próprio Ferréz), vem plantar uma das sementes da literatura marginal de periferia, que logo se alastraria pelo país via movimento de saraus periféricos.

Ferréz conta que escreveu o livro Capão Pecado depois da leitura da obra Cidade de Deus (1997), do escritor Paulo Lins, que trazia o contexto de violência urbana de uma favela do Rio de Janeiro. No ano de 2000, quando publicou seu primeiro livro, Ferréz procurou uma referência literária que identificasse aquela linguagem coloquial com gírias suburbanas, e encontrou no dramaturgo Plínio Marcos a alcunha de "escritor marginal", pois esse autor tirava da marginalidade suas personagens para o teatro. Daí se origina a ideia da literatura marginal que seria incorporada pelos poetas periféricos Sérgio Vaz (fundador da Cooperativa Cultural da Periferia - Cooperifa, que é crucial para o movimento de saraus) e Sacolinha (fundador da Associação Cultural Literatura Brasil) que já produziam seus poemas de forma independente em meados de 1990 nas favelas paulistas.

Com base na trajetória desses três escritores da literatura marginal, a antropóloga Érica Peçanha Nascimento (2006) descreve o perfil dos 
escritores periféricos como "representante das classes popularese moradores de bairros localizados nas periferias urbanas brasileiras" (NASCIMENTO, 2006, p. 19). O caráter de movimento literário se configura, também, a partir do envolvimento desses escritores marginais da nova geração em ações coletivas de interesse sociocultural: Ferréz, no Movimento 1 da Sul, Sacolinha, na Associação Cultural Literatura no Brasil, e Sérgio Vaz, na Cooperifa.

Outro marco que simboliza o surgimento da literatura marginal são as publicações de edições especiais da revista Caros Amigos, nos anos 2001, 2002 e 2004. Nas edições desta revista da editora Casa Amarela, muitos poetas periféricos publicariam seus primeiros poemas. Essas revistas inspiraram, na sequência, o surgimento do selo Literatura Marginal (L.M.), que lançou o livro Literatura Marginal: talentos da escrita periférica, em 2005, fortalecendo essa cena cultural periférica. Das palavras marginais do Ferréz, o organizador daquelas revistas especiais Caros Amigos e do Selo L.M., tentamos definir a literatura marginal-periférica como sendo "a literatura feita por minorias, sejam elas raciais ou socioeconômicas. Literatura feita à margem dos núcleos centrais do saber e da grande cultura nacional, isto é, de grande poder aquisitivo" (FERRÉZ, 2005b, p. 12-13 apud CORONEL, 2013, p. 30). Aqui, retomamos as "minorias" na condição social de maioria na voz política dos subalternos conforme criticado pela indiana Spivak, e neste artigo representada pela voz poética da Nívea Sabino.

\section{A cena e o circuito em Belo Horizonte}

Na cidade de Belo Horizonte, o Coletivoz Sarau de Periferia surgiu em 2008 a partir do contato com a literatura marginal-periférica do Sarau da Cooperifa, de São Paulo, que foi visitado por um grupo de poetas, atores, artistas da região periférica do Barreiro, na capital mineira. Depois de conhecerem o Sarau da Cooperifa, esse grupo de artistas iniciou as atividades do Coletivoz Sarau de Periferia no bar do Zé Herculano, no bairro Independência. Esse sarau completou em 2018 seus 10 anos de resistência e difusão da poesia/ literatura periférica em $\mathrm{BH}$, tornando-se uma referência reconhecida como precursora da cena literária marginal na região metropolitana de $\mathrm{BH}$ e no estado de Minas Gerais. Com isso, 
A maioria dos saraus periféricos de poesia que surgiram em Belo Horizonte teve origem no Coletivoz. E de um ano para cá, pipocaram por vários bairros e cidades. 'Houve necessidade de se criar referências em outros espaços geográficos da cidade. Muitos dos criadores de saraus que estão espalhados por $\mathrm{BH}$ e Região Metropolitana saíram daqui. [...] É muito importante você ir em um lugar onde sua voz é ouvida, se sentir um agente construtor", comenta um dos articuladores do Coletivoz, Rogério Coelho (BRANT, 2014).

Essa movimentação literária pioneira do Coletivoz inspira o nascimento de novos saraus marginais. Assim, surge em 2011 o Sarau Vira-Lata, que reforça aquela linguagem de contestação sociopolítica das vozes marginais por meio de uma atuação mais itinerante que realizava performances poéticas em praças no centro de $\mathrm{BH}$. Dos saraus Coletivoz e Vira-Lata, formou-se uma primeira geração mineira dessa nova cena literária marginal, em saraus como: dos Vagal (2012), do Ribeirão (2012), Comum (2013) , Apoema (2013), das Cachorras (2014), dos Lanternas (2014), Nosso Sarau (2014), Terra Firme (2015), dentre outros na região metropolitana e no interior do estado. No ano de 2014, nasceu o primeiro poetry slam de Minas Gerais em BH, o Slam Clube da Luta, que acontece toda última quinta-feira do mês com apoio do Coletivoz em parceria com o Teatro Espanca. Depois, nasceram novas comunidades de slams em Belo Horizonte e Minas Gerais, configurando uma segunda geração da cena, como: Slamternas, Slam da Estação, Slam das Manas, Slam Trincheira, Slam Valores, Slam A Rua Declama (Timóteo/MG), Slam Avoa Amor, Slam para Carolina (Sacramento/MG) etc.

Nessa repercussão reconhecida em torno dos saraus e slams por vários espaços de periferias em Minas Gerais, São Paulo etc., observamos a configuração de um Circuito de Saraus e Slams de Literatura MarginalPeriférica Contemporânea, pois, segundo o antropólogo urbano José Magnani da USP, o circuito é uma categoria que "descreve o exercício de uma prática ou oferta de determinado serviço por meio de estabelecimentos, equipamentos e espaços que não mantêm entre si uma relação de contiguidade espacial, sendo reconhecido em seu conjunto pelos seus usuários habituais" (MAGNANI, 2007, p. 21).

Este Circuito de Saraus e Slams da Literatura Marginal-Periférica extrapolou o âmbito nacional e vem se internacionalizando por meio de feiras, eventos, publicações de livros e pesquisas acadêmicas realizadas em outros 
países com interesse científico na literatura marginal. Nesse sentido, a pesquisadora e professora doutora de literatura da Universidade de Buenos Aires, Lucía Tennina, convidou escritores marginais de São Paulo para uma feira literária na capital argentina no mês de maio de 2014 (YAKINI, 2014). Outro exemplo dessa internacionalização desse circuito é o surgimento, em Belo Horizonte, do Slam Clube da Luta, que se conecta aos slams de São Paulo, Rio de Janeiro etc. O Clube da Luta teve, em 2014, o poeta e rapper João Paiva como campeão estadual, ganhador do slam nacional, em São Paulo, e representante do Brasil no GrandSlam, na cidade de Paris/França, no mês de maio de 2015. Nessa mesma esteira, a escritora mineira Pieta Poeta foi à França, nesse mesmo evento, representar o Brasil em 2019.

\section{vozes coletivas entram no espaco da literatura contemporânea}

Dessa breve contextualização sobre a literatura periférica dos saraus e slams marginais nas cidades de São Paulo e Belo Horizonte, percebemos a pluralidade e multiplicidade dos nichos da literatura contemporânea, pois não percorremos outras tendências da produção contemporânea nessa passagem do século XX para o XXI. Daí observamos, à luz da pesquisadora Regina Dalcastanè (1967), a disputa de poder na construção do espaço da literatura contemporânea. Essa autora constatou, ao analisar romances de editoras reconhecidas do campo literário brasileiro, a priorização de vozes de escritores homens, brancos, de classe média, com trânsito privilegiado em setores de legitimação dessa linha dominante nos meios jornalísticos e acadêmicos da crítica e do sistema literário concentrados no eixo São Paulo e Rio de Janeiro.

Portanto, a entrada daquelas vozes coletivas periféricas dos saraus/slams vem provocando ruídos em torno do "lugar de fala", conforme Regina Dalcastagnè, reconfigurando um subcampo na literatura contemporânea. Isso porque "na narrativa contemporânea é marcante a ausência quase absoluta de representantes das classes populares" (DALCASTAGNË, 2012, p. 18). Assim, o acesso à voz e à representação de múltiplos grupos sociais se tornou desafio situacional para o campo literário na literatura contemporânea. 
O campo literário - entendido no sentido de Bourdieu, isto é, o espaço social, relativamente autônomo, em que os produtores literários [...] geram critérios de legitimidade e prestígio (Bourdieu, 1992) - reforça essa situação, por meio de suas formas de consagração e de seus aparatos de leitura crítica e interpretação. Afinal, "todo julgamento de valor repousa num atestado de exclusão. Dizer que um texto é literário subentende sempre que outro não é" (COMPAGNON apud DALCASTAGNÈ, 2012, p. 20).

Com isso, a leitura analítica de publicações independentes à margem do campo literário, como o livro de poemas da escritora Nívea Sabino, abre a possibilidade de ampliação para diferentes vozes e corpos que disputam o espaço social da narrativa contemporânea. Ademais, o "lugar de fala" aqui toma outras proporções quando Nívea Sabino, mulher negra e periférica, reivindica uma voz e um lugar historicamente silenciados, subalternizados, subjugados dentro do campo literário. Essa tomada de posição da poeta conversa com a teórica bell hooks quando, na obra Intelectuais negras (1995), nos diz sobre a construção da mulher negra estar mais ligada ao corpo do que à intelectualidade, uma vez que elas se configuram, num contexto de racismo, como "intrusas" à conceituação branca ocidental de intelectual/ campo científico. Nesse sentido, a filósofa Djamila Ribeiro discorre sobre o tema em seu livro O que é lugar de fala? (2017), dialogando com diversas escritoras intelectuais negras. Recorremos a essa obra no que toca à poesia de Nívea Sabino quando esse "lugar de fala" é reivindicado como disputa de poder representativo frente ao campo literário contemporâneo, pois,

Um dos equívocos mais recorrentes que vemos acontecer é a confusão entre lugar de fala e representatividade. Uma travesti negra pode não se sentir representada por um homem branco cis, mas esse homem branco cis pode teorizar sobre a realidade das pessoas trans e travestis a partir do lugar que ele ocupa. Acreditamos que não pode haver essa desresponsabilização do sujeito do poder. A travesti negra fala a partir de sua localização social, assim como o homem branco cis. Se existem poucas travestis negras em espaços de privilégio, é legítimo que exista uma luta para que elas, de fato, possam ter escolhas numa sociedade que as confina num determinado lugar, logo é justa a luta por representação, apesar dos seus limites [...]. (RIBEIRO, 2017, p. 47). 
Nessa perspectiva filosófica, a representatividade da voz poética da Nívea Sabino pode se legitimar pelo lugar de fala do seu corpo político que vive a opressão racial, cuja experiência política é distinta se vivida por um escritor branco. Por isso, Djamila Ribeiro (2017) discute que "pessoas negras vão experienciar racismo do lugar de quem é objeto dessa opressão, do lugar que restringe oportunidades por conta desse sistema de opressão. Pessoas brancas vão experienciar do lugar de quem se beneficia dessa mesma opressão" (p. 48).

\section{nívea sabino, uma interiorana expandida pela performance}

Seguimos na trilogia do não faz mal: - mulher, negra e pobre! Ei, me diz, fala pra mim: Qual é a dor que te comove!?

(SABINO, 2016, p. 78)

Na tentativa de se estabelecer no mundo como cidadã, e compartilhar suas expectativas, anseios, utopias, denúncias, revoltas, em meio a um turbilhão de sentimentos que deságuam na escrita, Nívea encontra lugar na autorrepresentação - um elemento importante no desenrolar da cena performática que vai protagonizar. A autorrepresentação dita por Regina Dalcastagnè vai ao encontro das formas de representação de grupos marginalizados, em contraponto à tradição literária brasileira, e discute "as estratégias utilizadas por autores marginalizados (pobres, negros e moradores de regiões periféricas nas grandes cidades) para validar suas representações no campo literário brasileiro (pensado nos termos de Pierre Bourdieu), considerando ainda a recepção dessas representações em meio aos estudos literários" (DALCASTAGNĖ, 2007, p. 2-3).

A justaposição das palavras "lírica" e "favelada", no poema "Lírica de favelada" (SABINO, 2018, p. 114), revela o desejo de transgressão de uma contradição estabelecida pelas classes hegemônicas a esses termos. A emancipação anunciada pela escolha estética de ser lírica e favelada, com o suporte de mais espaços de atuação como os saraus, que permitem fazer e explorar sua voz, o que ainda não era possível no tempo de Carolina Maria 
de Jesus, é um ato político de sua autorrepresentação. Autorrepresentase como forma de expressar seu lirismo, ainda que moradora de favela. E não é por outro meio, que não o da poesia, que se confirma uma forma de legitimidade - legitimadora em seu lugar de fala.

Para além disso, há também a representação de seus lugares de origem, de suas histórias pessoais e vivências. O caráter autobiográfico de alguns poemas eleva o nível de discussão em torno do que é falar de si, por meio da apresentação do poema nos saraus. Quem é este eu-lírico, que se revela verdadeiro, constituído por uma estética, um jogo emocional catártico, também reflexivo, e busca envolver o espectador de forma que este tome parte de seu conteúdo, de suas próprias questões?

O condicionamento dos elementos da vida se converte em tema amplamente questionador do modo de viver, das condições de subalternidade, da cor, da desigualdade de gênero e orientação sexual. A escrita expõe um roteiro de ações que busca convencer, escancaradamente, de que há um lugar demarcado na fala, na vida, na voz, no corpo. A escrita vociferada nos saraus/ slams ainda ganha a dimensão da presença corporal em sua plenitude de ato em performance. Para que a escrita seja ouvida e sentida no embate com quem fala e se afirma como poeta, como poeta marginal, periférico/a. Nesse ponto, radicalizamos a visão sobre um elemento fundante no momento da performance da poesia falada: o corpo.

De alguma forma, o corpo presente nos saraus e slams sempre está ativo pelo público, que atua constantemente, manifestando-se e trocando de lugar com quem o apresenta. Ademais, Zumthor revela sua experiência do "corpo latejante", quando descreve a cena costumeira de um cantador de rua, nas proximidades da rua Faubourg Montmartre, à rua Saint-Denis.

Ora, o que percebíamos dessas canções? Éramos quinze ou vinte troca-pernas em trupe ao redor de um cantor. Ouvia-se uma ária, melodia muito simples, para que na última copla pudéssemos retomá-la em coro. Havia um texto, em geral muito fácil, que se podia comprar por alguns trocados, impresso grosseiramente em folhas volantes. Além disso, havia o jogo. O que nos havia prendido era o espetáculo. Um espetáculo que me prendia, apesar da hora de meu trem que avançava e me fazia correr em seguida até a Estação do Norte. Havia o homem, o camelô, sua parlapatice, porque ele vendia as canções, apregoava e passava o chapéu; as folhas-volantes em bagunça num guarda-chuva emborcado na beira da 
calçada. Havia o grupo, o riso das meninas, sobretudo no fim da tarde, na hora em que as vendedoras saíam de suas lojas, a rua em volta, os barulhos do mundo e, por cima, o céu de Paris que, no começo do inverno, sob as nuvens de neve, se tornava violeta. Mais ou menos tudo isto fazia parte da canção. Era a canção. Ocorreu-me comprar o texto. Lê-lo não ressuscitava nada. Aconteceu-me cantar de memória a melodia. A ilusão era um pouco mais forte, mas não bastava, verdadeiramente (ZUMTHOR, 2014, p. 32).

A sensação de "vazio" na leitura de Zumthor faz referência à ausência do corpo, das pessoas, do espaço carregado de representações que se podia perceber. Assim, como na descrição, o ambiente diverso dos saraus e slams, como já relatado, garante ao público um movimento da palavra que nunca se encerra na escrita. A presença de um corpo que recita amplia a visão/ audição dos códigos da palavra, fazendo com que se perceba (receba) a presença aqui-agora como elemento fundamental ao ato da performance: transmissão-falante e recepção-ouvinte.

O poema de Nívea Sabino, por vezes recitado entre tapas na própria cara, movimentos de dedo em riste em direção ao público, afirma-se como denúncia reexistente. O confronto com o público presente, muitas vezes, sugere uma autorrepresentação marcada por um corpo que denuncia, que se resguarda na ancestralidade de Nzinga e Dandara, evocando forças a que sustentar o presente ainda marcado pelo racismo, pela desigualdade. 0 corpo de Nívea, no momento que recita, parece-nos hipertextos em forma de movimentos, que colaboram com o texto previamente escrito. Escrita e corpo confluem-se num jogo, num ritual, de afirmar-se negra e utilizar de todas as grafias afro-brasileiras para autorrepresentar-se. Trazer o corpo aqui para a cena performativa da palavra em forma de poesia faz do slam um espaço para experimentações e "formas-força" que nos fazem pensar na literatura expandida, como modo de ler: o corpo negro de Nívea, suas nuances e provocações na atuação, o embate político reverberado pelas direções de sua fala, a história dentro da História, o jogo entre o ficcional e o testemunho que esse corpo-voz traz à cena, entre outros elementos que podem ser acessados na performance.

Podemos ver, em parte, a atuação de Nívea em vídeo. Porém, devemos considerar a presença na performance ao vivo como recepção fundamental, pois ali todos os elementos funcionam concomitantemente: o dia em 
questão, o noticiário atual, a condição do público presente, a metereologia, o espaço da apresentação, o tipo de evento em si, entre tantas outras condições que fazem da performance um elemento vivo e presencial.

Na performance poética ao vivo, do poema "Seguimos na trilogia do não faz mal" (SABINO, 2018. p. 112) ou no vídeo acessivel no site YouTube, o "sentir na cara, ..." é seguido de um gesto de tapa com as mãos que a performer faz em sua face, impactando a recepção do leitor-público, reforçando que "a performance é o ato de presença no mundo e em si mesma. Nela o mundo está presente" (ZUMTHOR, 2014, p. 67).

Performance da Nívea Sabino no $1^{\circ}$ Slam Estadual, 07/12/2016

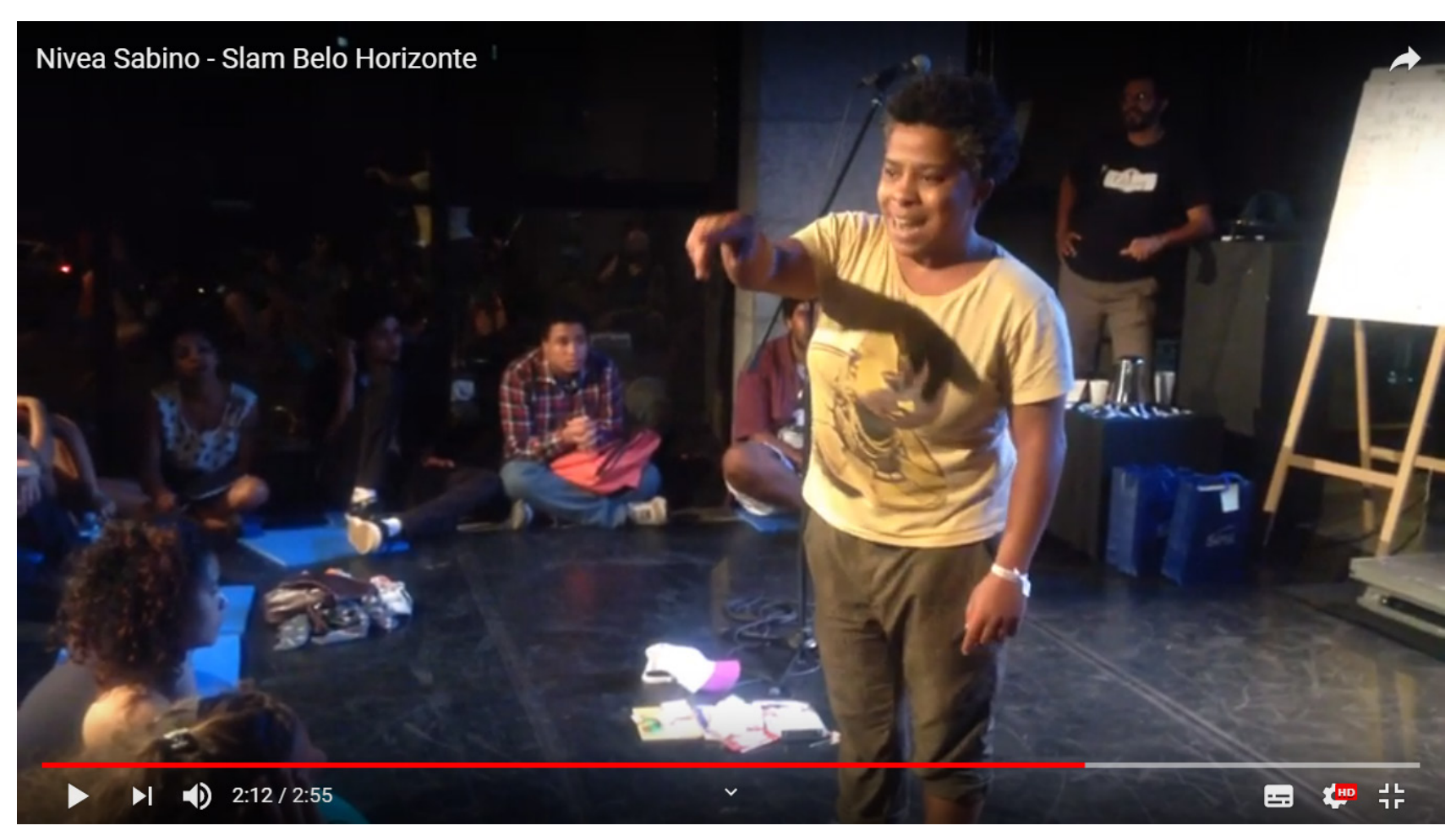

Fonte: https://www.youtube.com/watch?v=WOE8L vLnfw\&t=24S

Antes desse gesto, Nívea, nesse mesmo poema, já chama atenção paras aquelas vozes, corpos (citados na epígrafe desta parte do artigo) e para o espaço social em disputa por inclusão na sociedade e na literatura contemporânea. Assim, a poeta questiona "Quem insiste no 'não': / - 'Não há machismo' / - 'Não há racismo...' / Não há é na sua rotina, de ir e vir, vivência pra te mostrar!" (SABINO, 2018. p. 112). Aí vemos que ainda persiste a exclusão das vozes e corpos das mulheres, negras, pobres, e a poesia em 
performance as torna visíveis no espaço do campo literário contemporâneo, ou naquele espaço do evento.

O eu-lírico da poeta se posiciona no combate às violências patriarcalheteronormativa e étnico-racial sofridas pelo corpo daquela "mulher, negra e pobre!" do segundo verso da epígrafe de abertura. No espaço dessa rotina em sociedade que a performance poética encena, percebe-se uma estratégia de busca de legitimidade pela experiência vivida pela autora, a mesma legitimação buscado por Carolina Maria de Jesus ou Ferréz em suas obras literárias. Isso é analisado pela crítica Regina Dalcastagnè (2012) da seguinte forma: "A autora de Quarto de Despejo [...] compreende sua posição periférica no campo literário, adotando estratégias que permitam superála, sobretudo pela valorização da experiência vivida e da autenticidade discursiva" (p. 47). "Ferréz também busca se legitimar via autenticidade na contracapa de Ninguém é inocente, ele diz 'morar dentro do tema' [...] apresenta-se [...] como aquele que briga nas bordas do campo literário" ( $p$. 45).

Esse recurso de legitimação vivencial e corporal é reiterado por Sabino (2018, p. 112), que convoca o olho/ouvido do leitor, o público, recitando "Vem cá / cola ni mim / vão dar um rolezinho pro cê sentir: / - Sentir na cara, ...a negligência! / Sentir na cara, ....a indiferença! / Sentir na cara, ...a violência!". A autora retoma aqui os fatos de segregação e higienização racial nas cidades quando se proibiu a entrada de grupos de jovens negros em shoppings. Estes acontecimentos ficaram conhecidos como "rolezinhos", os quais dizem do "lugar de fala" daqueles que vivem diariamente a opressão do racismo.

Essa variável da segregação urbana, do "rolezinho" nesse poema, é pertinente na elucidação dos espaços possíveis na literatura contemporânea analisados por Regina Dalcastagnè (2012), uma vez que a "urbanização, desterritorialização, transformações nas esferas pública e privada, segregação [...] são alguns elementos que, combinados entre si, podem ajudar a entender melhor a configuração espacial da narrativa dos nossos dias" (p. 111).

O ato de dizer, por vezes, com voz embargada pela emoção, "Eu, permaneço de pé/ armada pela palavra/ reverenciando gerações passadas/ representando milhões de minorias diariamente silenciadas" (SABINO. 2018. p. 113) sugere-nos, somente no texto escrito, uma ação. Nessas 
segregações sofridas pelos corpos femininos e negros, Nívea Sabino recoloca a memória de resistência e insubordinação nos versos por inclusão e igualdade. Sua performance ao vivo revela pontos enérgicos de sua projeção vocal nas frases de efeito. Sua expressão corporal, agitada, incomodada e pulsante, eleva o tom na explanação da importância de "estar de pé", quando recita antes dessa estrofe: "É que Rosa Parks se recusou sentar, pra eu chegar até aqui, onde estou. / Carolina de Jesus escreveu sua rotina em papéis e revistas que sequer ela os tinha. / Resistiu da maneira que conseguia. / Cláudia, não houve quem não viu, que o homem arrastou".

A poeta, nessas quinta e sexta estrofes, retoma a resistência da mulher negra, escritora e pobre trazendo a memória histórica e contemporânea de três mulheres negras pobres: Rosa Parks (negra ativista nos EUA), Carolina Maria de Jesus (escritora negra), Cláudia (moradora negra de favela no Rio de Janeira). Contextualizar as personagens históricas, de mulheres negras, subjugadas, silenciadas, mortas pelas forças do racismo, na performance de Nívea, assimila-nos uma visão de que a poeta se "veste" de suas peles, assim como de suas lutas e reexistência. Parece reivindicar tanto o lugar de poder a elas, que o racismo tenta apagar, diminuir, assentar na história, quanto reinveste em si própria, em sua própria voz, o direito de não ser silenciada; de estar de pé, como de fato se mostra com sua presença diante do público.

A implicação desse "eu", um eu-lírico, na performance nos sugere também o eu-empírico. "Permanecer de pé", na presença do corpo que fala, emitenos uma singularidade de estar de pé com a sua palavra atualizada; com sua atividade poética viva e reavivada pelo ato de recitar. A palavra, assim, "não vive presa na livraria", mas na oralidade que se transforma em vocalidade viva, no encontro, na disseminação ao vivo que proporciona confrontos existenciais no dia a dia.

A poética de Sabino completa e demarca aí uma ancestralidade negra e feminista em sua escrita contemporânea, o que reforça o dito por Dalcastagnè em sua crítica à literatura contemporânea pelo "constrangimento" ao seu espaço, tendo em vista a ocupação de seu território contestado por

corpos silenciados, domesticados, esquecidos nos quartos de despejo; corpos insubordinados, que insistem em ocupar lugares que não lhes são destinados; corpos que negam o discurso alheio sobre si - são esses corpos, cheios de marcas e 
rasuras que preenchem nossas cidades, e que podem dar sentido à nossa literatura (DALCASTAGNÈ, 2012, p. 144).

Esse sentido literário dado por Nívea em que "Minha poesia hoje pede passagem é pra mulherada/ que não pede o direito à fala, / vai pra rua e ocupa / escarra tudo à arte / pra ver se atinge a meta máxima: o dia em que TODAS SERÃO LIVRES" (SABINO, 2018. p. 113) é, talvez, uma janela que se transforma em literatura/ação coletiva num sarau ou slam, abrindo caminhos de inclusão e democratização do fazer literário e do direito à literatura. Podemos dizer que entre a performance e o texto escrito no livro não há sobreposições. Nesse interstício, multiplicam-se as possibilidades de leituras à medida que se utilizam mais e mais elementos passíveis de leituras. Entre o suporte do livro e o suporte do corpo presente, alternam-se presenças, reminiscências, memórias de corpos e vozes advindas das minorias políticas, sociais, identitárias e étnico-raciais renovadas e/ou reconhecidas por muitos desses grupos. Há um expandir possível pela legitimação de vozes segregadas, silenciadas ao longo da história, para além das fronteiras ou limites desse "entre" vocalizado e caligrafado.

Ainda resta ponderar mais sobre esse "entre". "Entre a performance e a escrita", título que encabeça este artigo, como vimos em partes de textosperformances de Nívea Sabino, aponta-nos para além de um interstício, ou de um vazio. Ali, preenchem-nos múltiplos signos de representação, tanto da fala, quanto da escrita, capazes de povoar conceitos aproximados de uma literatura expandida. Em consideração a isso, trazemos aqui um conceito de "encruzilhada" visto na obra da professora doutora Leda Maria Martins (1955) em seu vasto repertório sobre elementos da performance realizada por grupos e artistas negros.

"Encruzilhada", não apenas como lugar de encontro, mas de confronto de saberes atuais x ancestrais; corpo x palavra; escrita x literatura, entre outros, sugere-nos um embricamento nada casual quando o assunto é poesia falada. O trabalho sobre as performances de Nívea Sabino, assim como demais poetas negras do slam, chama-nos atenção para este específico "entre". A poesia de Nívea, carregada de referências históricas, de mulheres negras, personalidades e vítimas de racismo, ocorre no entrecruzamento com seu próprio corpo em movimento. A narrativa deixa de ser per si, e passa a coexistir com outras, nessa encruzilhada. 
Em Afrografias da memória: o reinado do Rosário do Jatobá (1997), Leda Maria Martins nos revela uma identidade mantida, recontada, recantada, nas histórias e nos cânticos dos congadeiros da Irmandade, que são autores(as) tanto quanto os(as) ancestrais africanos. Em Nívea, vemos a reivindicação de um lugar histórico e, ao mesmo tempo, presente, quando o ato da palavra oralizada e seu corpo marcam, evidentemente, o agora. A performance, manifestada na presença, retoma o saber filosófico da cultura banto e afrobrasileira, conduzidas pelos rituais de onde surge o que Martins declara ser uma "cultura de encruzilhada".

A encruzilhada, locus tangencial, é aqui assinalada como instância simbólica e metonímica, da qual se processam via diversas de elaborações discursivas, motivadas pelos próprios discursos que a coabitam. Da esfera do rito e, portanto, da performance, é o lugar radial de centramento e descentramento, interseções, influências e divergências, fusões e rupturas, multiplicidade e convergências, unidade e pluralidade, origem e disseminação. Operadora de linguagens e de discursos, a encruzilhada, como um lugar terceiro, é geratriz de produção, as noções de sujeito híbrido, mestiço e liminar, articulado pela crítica pós-colonial, podem ser pensadas como indicativas de efeitos de processos e cruzamentos discursivos diversos, intertextuais e interculturais (MARTINS, 1997, p. 28).

Neste artigo, procuramos evidenciar apenas alguns aspectos desse "entrelugar" ou a "encruzilhada" das autorrepresentações poéticas performáticas dos slams/saraus, como espaços simbólicos de manifestações artísticas. Espaços do campo literário contemporâneo em que os atravessamentos constantes entre saberes, vivências, experiências corroboram a criação de limiares do saber ali construído; reconfigurado; híbrido de elementos simbólicos, políticos, éticos e estéticos. O corpo polítco performático presente, a diversidade de temas e propósitos poéticos, no ato da cena da competição/jogo do slam, formam um conjunto de elementos potencialmente passíveis de cruzamentos. Autorrepresentar-se nesses espaços, queretomammemória, gestos, cantosereferências da ancestralidade e dos antepassados afrodescendentes, munindo-se das consequências atuais do sistema escravista e colonial, com marcas presentes no cotidiano, sugere-nos encruzilhadas. 
[...] é pela via dessas encruzilhadas que também se tece a identidade afro-brasileira, num processo móvel, identidade esta que pode ser pensada como um tecido e uma textura, nos quais as falas e os gestos mnemônicos dos arquivos orais africanos, no processo dinâmico de interação com o outro, transformam-se e reatualizamse continuamente, em novos diferenciados rituais de linguagem e de expressão, coreografando a singularidade e alteridades negras (MARTINS, 1997, p. 26).

Termo mais que essencial para o trabalho de Nívea Sabino é o que Leda Maria Martins chama de "oralitura", em seu texto Performances da oralitura, corpo lugar da memória (2013). Parece-nos evidente a aproximação desse conceito ao que revela a obra de Nívea, uma vez que ela se concentra num lugar criado para a recitação de poesias autorais quando a "performance indica a presença de um traço cultural estilístico, mnemônico, significante e constitutivo, inscrito na grafia do corpo em movimento e na velocidade" (MARTINS, 2001, p. 84).

Assim, consideramos que esse "entre" é também "encontro". Nos poemas de Nívea Sabino, encontram-se vozes marginais das excluídas socialmente, que se estreitam no poder de sua fala. Encontram-se vozes antepassadas e ancestrais, que se legitimam na presença, no presente. Encontram-se corpos rasurados pelo racismo, como o seu próprio corpo, revigorado e autoproclamado livre. Num caminho que seu corpo faz por entre as gentes, Nívea (2018, p. 23) nos entrecruza e entrelaça pelo: "Caminho / Neste mundo vasto / De encontros de acasos / Profundo acaso / Ou destino / Do meu passo / No sem lugar / Para o qual / Eu me laço".

\section{referências}

BRANT, Ana Clara. "Saraus de Poesia se espalham por BH e conquistam público diversificado". Em Cultura, 2014. Disponível em: $<$ https://divirtase.vai. com.br/app/noticia/arteelivros/2014/05/18/noticia arte e livros,154799/ vozdaperiferia.shtml>. Acesso em: 6 Jul. 2015.

CORONEL, Luciana Paiva. A escrita da cidade partida: identidade e alteridade em Capão Pecado. Est. Lit. Bras. Contemp., Brasília, n. 42, p. 29-45, jul./dez. 2013. Disponível em: <https://www.scielo.br/pdf/elbc/n42/02.pdf>. Acesso em: 06 jul. 2015 . 
DALCASTAGNĖ, Regina. A autorrepresentação de grupos marginalizados: tensões e estratégias na narrativa contemporânea. Letras de Hoje, Porto Alegre, v. 42, n. 4, p. 18-31, dez. 2007.

Literatura brasileira contemporânea: um território contestado. Vinhedo: Horizonte/Rio de Janeiro: UERJ, 2012.

D'ALVA, Roberta Estrela. Um microfone na mão e uma ideia na cabeça - o poetry slam entra em cena. Synergies Brésil, n. 9, p. 119-126, 2011. Disponível em: https://gerflint.fr/Base/Bresilg/estrela.pdf. Acesso em: 12 set. 2019.

FELIX, Camila. Atlas dos Saraus de Belo Horizonte: mapeamento dos saraus de poesia da região metropolitana de Belo Horizonte. Belo Horizonte: Ed. Crivo, 2016.

HOOKS, bell. Intelectuais negras. Revista Estudos Feministas, Santa Catarina, v. 3, n. 2, p. 465-478, 1995. Disponível em: <https://periodicos.ufsc.br/index. php/ref/article/view/16465/15035>. Acesso em: 25 set. 2017.

LINS, Paulo. Cidade de Deus. São Paulo: Companhia das Letras, 1997.

MAGNANI, J.GUILHERMEC.; BRUNA MANTESE(Orgs.). Jovens na metrópole: etnografias de lazer, encontro e sociabilidade. São Paulo: Ed. Terceiro Nome, 2007.

MARTINS, Leda Maria. A cena em sombras. São Paulo: Perspectiva, 1995.

- Afrografias da memória: o reinado do rosário do jatobá. São Paulo: Perspectiva, 1997.

- Performances da oralitura: corpo, lugar da memória. Revista do Programa de Pós-Graduação em Letras, [S.I.], n. 26, p. 63-81, nov. 2013. ISSN 2176-1485. Disponível em: <https://periodicos.ufsm.br/letras/articlel view/11881>. Acesso em: 2 out. 2018.

. Performances do tempo e da memória: os congados. O Percevejo - Revista de Teatro, Crítica e Estética, Rio de Janeiro, ano 11, n. 12, p. 68-83, 2003

RIBEIRO, Djamila. O que é: lugar de fala? Belo Horizonte: Letramento: Justificando, 2017. 
SABINO, Nívea. Interiorana. Ilustração de Júpiter Coroada. Brasília; São Paulo: Padê Editorial, 2016.

. Interiorana. 2. ed. Nova Lima: Sem Editora, 2018. Disponível em: $<$ https://niveasabino.com/index.php/interioranal>. Acesso em: 22 maio 2020.

SPIVAK, Gayatri Chakravorty. Pode o subalterno falar? Trad. Sandra Regina Goulart Almeida, Marcos Pereira Feitosa, André Pereira. Feitosa. Belo Horizonte: Editora UFMG, 2010 [1985].

YAKINI, Michel. Que pasa, sarau? Brasil de Fato. 2014. Disponível em:<https:/l www.brasildefato.com.br/node/27923 >. Acesso em: 8 jul. 2015.

ZUMTHOR, Paul. Performance, Recepção, Leitura. Tradução de Jerusa Pires Ferreira e Suely Fenerich. São Paulo: Cosac Naify, 2014.

Artigo recebido em: 21/01/2020

Aceito: $24 / 06 / 2020$ 